\title{
Pleomorphic Adenoma of the Sublingual Salivary Gland - A Rare Occurrence
}

\author{
Authors \\ Ankur Chaurasia ${ }^{1}$, Nalini Bhat ${ }^{2 *}$, Susan Cherian ${ }^{3}$ \\ ${ }^{1}$ Resident Medical Officer in ENT, Dept of ENT, BARC Hospital, Anushaktinagar, Mumbai 400094, India \\ Email: ankur306@gmail.com \\ ${ }^{2}$ Consultant and Head, Dept of ENT, BARC Hospital, Anushaktinagar, Mumbai 400094, India \\ ${ }^{3}$ Consultant \& Head, Dept of Pathology, BARC Hospital, Mumbai 400094, India \\ Email: cheriansusan@yahoo.com \\ *Corresponding Author \\ Nalini Bhat \\ Email:nbhat@barc.gov.in
}

\begin{abstract}
Sublingual salivary gland tumours are very rare and most, that occur, are malignant. A case of pleomorphic adenoma of the sublingual salivary gland, presenting as a slow growing swelling in the floor of the mouth, is presented for its rarity. The literature is also reviewed.
\end{abstract}

Keywords: Salivary gland tumour, Sublingual gland, Pleomorphic adenoma, Benign.

\section{Introduction}

Salivary gland tumours are rare, with an incidence of 2.5-3/1 lakh population, and those in the sublingual glands are rarer making up only $1 \%$ of all salivary gland tumors. A benign sublingual gland tumor is an even rarer entity as $70-90 \%$ of sublingual gland tumours have been reported to be malignant. ${ }^{[1]}$ Pleomorphic adenomas though the commonest salivary gland tumour, occurs mostly in the parotid gland $(84 \%), 8 \%$ in the submandibular gland, $6.5 \%$ in the minor salivary glands and $0.5 \%$ in the sublingual glands. ${ }^{[2]}$ Till date there are very few cases of pleomorphic adenoma of the sublingual gland reported. Andreasen et al who studied sublingual gland tumours over 35 years in Denmark reported a total of only 29 cases, of which 28 were malignant and one was a benign pleomorphic adenoma. ${ }^{[3]}$

\section{Case report}

A 31-year-old lady reported to our OPD, in March 2017, with a slightly painful swelling, that interfered with eating, in the floor of her mouth. The swelling was noticed 10 years ago, when it was smaller, and had been gradually increasing. She was on thyroid hormone supplements to correct her hypothyroidism and had no other positive medical, obstetric or surgical history. Intraoral examination revealed an oval swelling in right floor of mouth, $3.5 \mathrm{~cm} \mathrm{x} 2 \mathrm{~cm}$, extending into the submandibular triangle. It was firm, well circumscribed, not tender and non-pulsatile with few whitish petechiae on its surface. A patent Wharton's duct opening was seen medial to the swelling (Figure 1). Laboratory investigations were normal. 


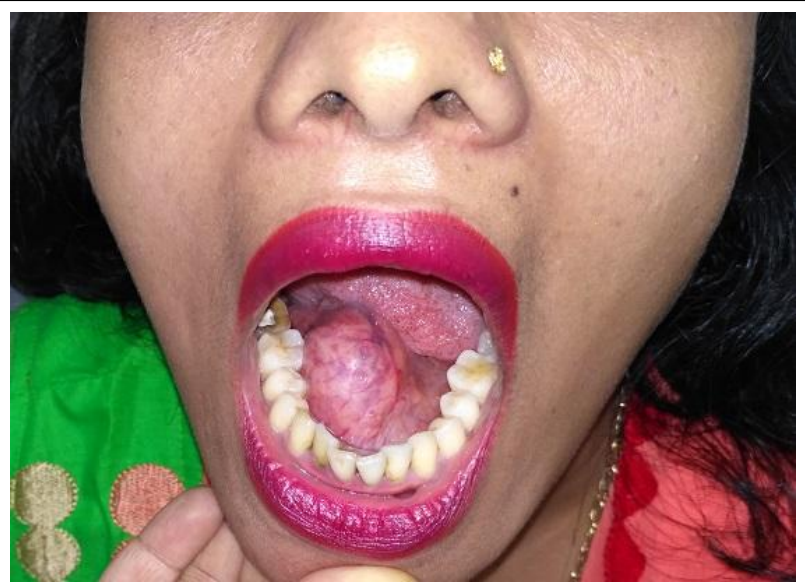

Figure 1 showing swelling in right side floor of mouth with patent Wharton's duct opening medial to swelling.

Ultrasonography (USG) showed a solid, well defined, focal mass in right submental space without calcification. Lesion was not infiltrating adjacent structure and separate from submandibular gland. Magnetic resonance imaging (MRI) showed a welldefined, lobulated lesion on right floor of mouth, measuring $4.4 \mathrm{~cm} \times 2.5 \mathrm{~cm} \times 4 \mathrm{~cm}(\mathrm{AP} \times$ Transverse $\times$ Superoinferior). It extended upto the genioglossus muscle laterally, myelohyoid inferiorly and genioglossus medially. Laterally it abutted the lingual cortex of mandible without eroding it. The tumor was hypo to isointense on T1and hyperintense on T2weighted images with a heterogeneous post contrast enhancement. Ipsilateral dilated Wharton's duct with normal submandibular gland was seen. Fine needle aspiration cytology (FNAC) established the salivary gland origin of the tumour and further classified it as a pleomorphic adenoma (Figure 2).

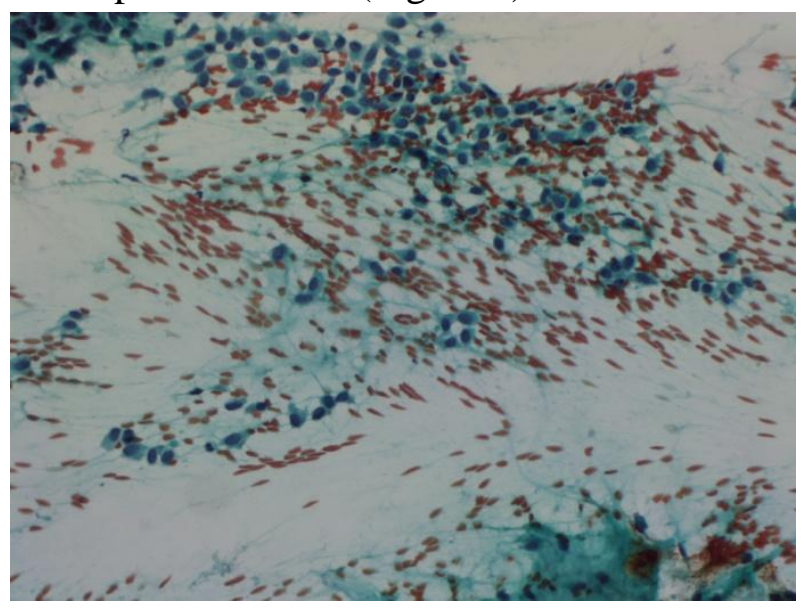

Figure 2: The epithelial cells are small round and uniform, some plasmacytoid with fine chromatin, small nucleoliand delicate cytoplasm. The stromal tissue is seen in lower right. (PAPx200).

Right side sublingual gland mass excision was performed under general anesthesia. The mucous membrane of the floor of the mouth was incised anterior to Wharton's duct and flap raised, and sublingual gland and swelling resected as a single mass. The tumor did not adhere to the surrounding tissue (Figure 3).

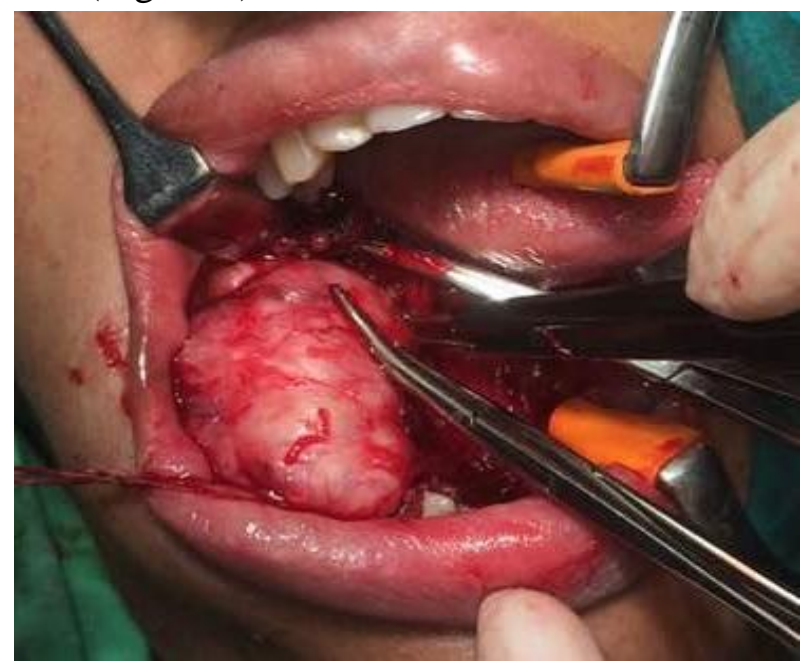

Figure 3 shows lesion insitu.

Gross morphology was a well circumscribed and capsulated tissue $4 \times 3 \times 1.5 \mathrm{~cm}$ with external boss elation and congestion. On cut section grayish white to tan color firm, nodular tumor was seen with multiple fibrous septae in between giving a lobular appearance. At one end, adjacent $1 \times 1 \times 1 \mathrm{~cm}$ soft area, resembling normal salivary gland tissue, was seen. (Figure 4)

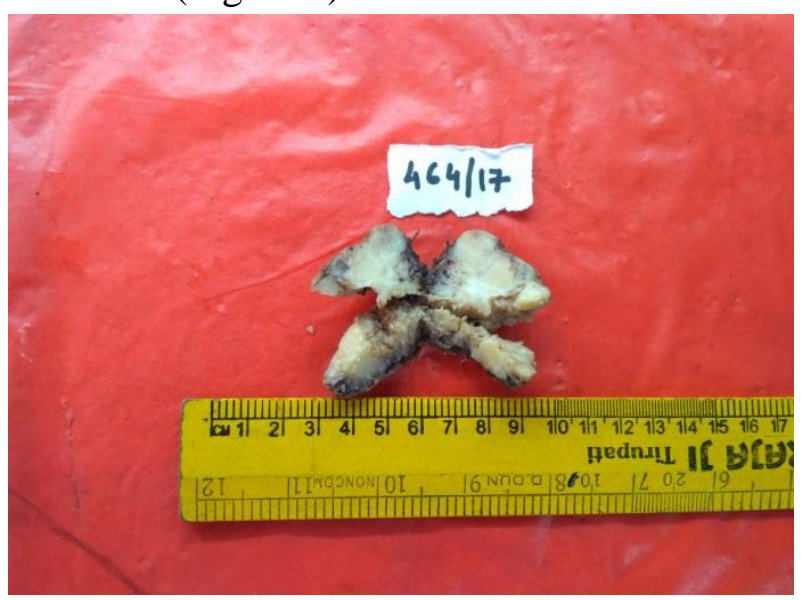

Figure 4 Gross appearance shows a rubbery well circumscribed mass with a bosselated surface. Cut surface is solid with glistening areas indicative of 


\section{JMSCR Vol||06||Issue||06||Page 550-554||June}

cartilaginous differentiation. Normal salivary gland is seen in the lower part of the specimen.

Histopathology confirmed the preoperative FNAC diagnosis of a pleomorphic adenoma. It was a well circumscribed encapsulated biphasic tumor composed of epithelial and mesenchymal components. The epithelial component was arranged as tubules, trabeculae, sheets of cells and acini having two cell layers. The mesenchymal component was composed of mucous, myxoid, fibromyxoid and chondroid tissue. The fibrous capsule showed occasional foci of tumor extension into the capsule. Mucinous salivary gland acini were seen adjacent to tumor capsule in one focus (Figure 5A-5C) Postoperative period was uneventful with good healing, a patent Wharton's duct and no neurologic damage.

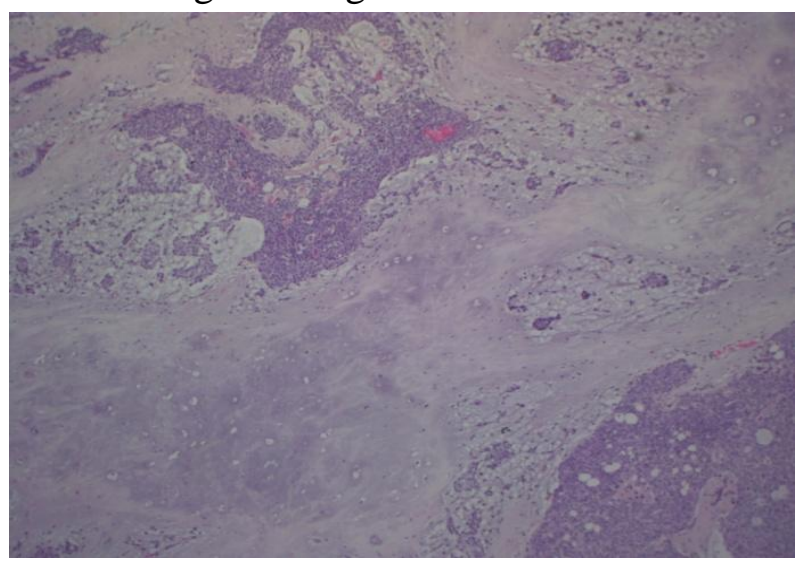

Figure 5A - Section shows the biphasic appearance of the tumour with admixture of the epithelium and stroma. Stroma is fibromyxoid with cartilaginous differentiation. (H\&Ex40)

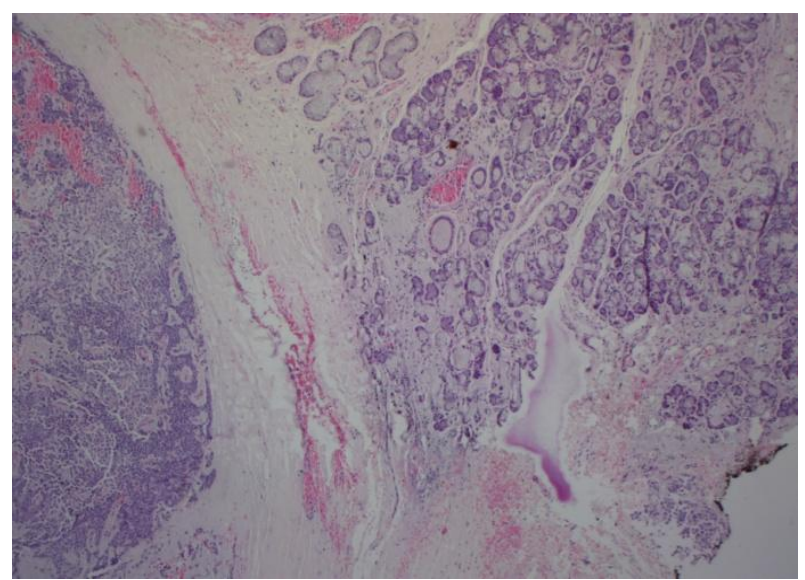

Figure 5B - Section shows the tumour margin with the normal predominantly mucinous salivary gland on the right. (H\&Ex40)

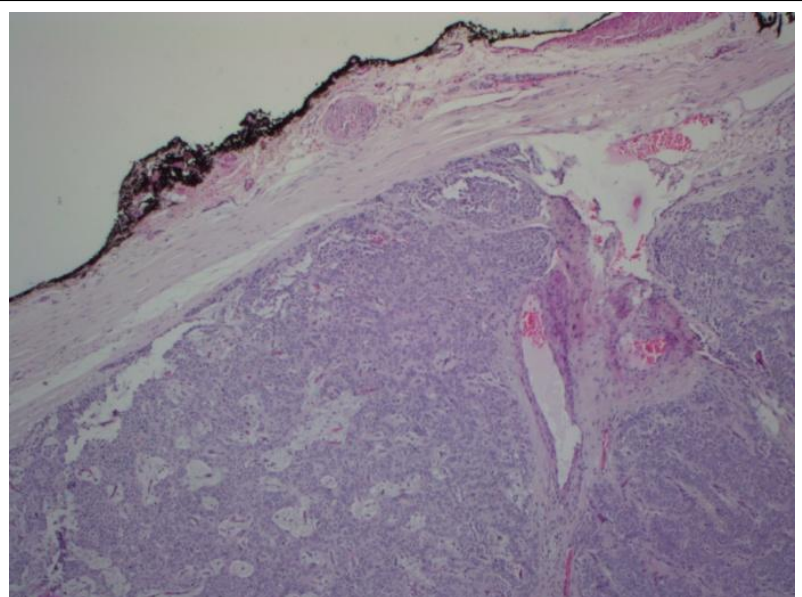

Figure 5C - Section shows capsule penetrated by tumour and extending till the inked surgical margin. (H\&Ex40)

\section{Discussion}

The differential diagnosis in this case included non-neoplastic entities of salivary glands such as ranula and chronic sialadenitis, a dermoid cyst and neoplasms of salivary glands of submandibular/ sublingual/minor salivary glands origin.

Exact preoperative evaluation of such a mass is necessary to diagnose, treat and prognosticate, but it can be challenging. USG has a high sensitivity (approximately $100 \%$ ) for differentiating intraglandular from extraglandular tissue. ${ }^{[4]}$ In our case, USG showed the tumour was solid, noninfiltrating and not involving the submandibular gland.

Fine needle aspiration cytology (FNAC) is a very useful method for evaluating suspicious salivary gland mass due to its low cost, minimum morbidity and rapid turnaround time. Metaanalysis of published series indicates $96 \%$ sensitivity and $98 \%$ specificity for neoplasia, whereas distinction between benign and malignant neoplasms has $79 \%$ sensitivity and $96 \%$ specificity $^{[5]}$. In our case FNAC could provide the diagnosis of a pleomorphic adenoma as typical constituents namely epithelial and myoepithelial cells in the characteristic fibrillary and chondromyxoid matrix were seen. In view of the relatively large size of the mass in this case sampling was done from different areas. The proportion of cellular constituents are extremely 
variable from one Pleomorphic adenoma to another, and within an individual tumour hence it is important to sample different areas of the tumour with multiple passes $^{[6]}$.

MRI is the investigation of choice to assess the exact extent, surrounding invasion, perineural spread and lymph node staging. It also eliminates dental artifacts and distinguishes tumour from obstructed secretions. It however cannot differentiate benign from malignant masses. Recently, new MRI techniques, such as dynamic contrast-enhanced MRI (DCE-MRI), diffusion-weighted MRI (DW-MRI), and proton MRI spectroscopy, have shown promising results in this aspect. $^{\text {[7] }}$

Histologically, a pleomorphic adenoma is also called benign mixed tumor as it consists of a biphasic population of epithelial and mesenchymal cells in varying proportions in a background stroma. Foci of microscopic extensions extending beyond the capsule may be seen. ${ }^{[8]}$ Hence wide local excision, and not enucleation, is the recommended treatment. Sun et al reported that for benign sublingual glandtumours, the resection of tumour and sublingual gland is the preferred treatment ${ }^{[9]}$. The histopathology in our case showed occasional foci of tumour extention into the capsule and the patient has been kept on a regular follow up.

Although the etiology of pleomorphic adenoma is unknown, the incidence of this tumor has been found to increase $15-20$ years after exposure to radiation. ${ }^{[8]}$ Pleomorphic adenomas are known to occur in all age groups and are more common in women. Overexpression of PLAG1, involved at $8 \mathrm{q} 12$ chromosome, is essential for the tumorigenesis of pleomorphic adenomas, although the mechanisms of over expression are variable. ${ }^{[10]}$ The prognosis for pleomorphic adenomas is good, but recurrence is reported in $0.4-5 \%$ of cases ${ }^{[11]}$ and malignant transformation occurs in about $6 \%$ cases. ${ }^{[12]}$ Soares et al have demonstrated that overexpression of mucin 1 gene (MUC1) was related to recurrence and malignant transformation. ${ }^{[13]}$

\section{Conclusion}

Benign Pleomorphic adenoma of the sublingual salivary gland is extremely rare.Wide excision though recommended is difficult in case of large tumors due to location of the gland. Regular follow up is also recommended.

\section{References}

1. Speight P, Barrett A. Salivary gland tumours. Oral Diseases 2002;8:229_ 40.[Pubmed]

2. Som PM, Curtin HD. Head and neck imaging, 3rdedn, Vol. 2. St. Louis, MO: Mosby; 1996. p. 877-912.

3. Andreasen, S., Bjørndal, K., Agander, T.K. et al.Tumours of the sublingual gland:a national clinicopathological study of 29 cases. Eur Arch Otorhinolaryngol (2016)273:3847. https://doi.org/10.1007/s00405-016-4000-y

4. Weber AL. Imaging of the salivary glands. CurrOpinRadiol1992;4:117-22. [Pubmed]

5. Schmidt RL, Hall bJ, Wilson AR, Layfield LJ. A systematic review and meta-analysis of the diagnostic accuracy of fine needle aspiration cytology for parotid gland lesions. Am J Clin Pathol.2011: 136(1):4559

6. Krane JF, Faquin WC. Chapter10 Salivary glands, Cytology: Diagnostic principles and clinical correlates,Edt: Cibas ES, Ducatman BS, $3^{\text {rd }}$ edition;p285-286

7. Thoeny HC. Imaging of salivary gland tumours. Cancer Imaging 2007;7(1):5262.[PMC]

8. El-Nagger A.K, Chan J.K.C,Grandis J.R, Takata T, Slootweg P.J. WHO Classification of Head and Neck Tumours, 4th edn. IARC:Lyon;2017. p.185-6.

9. G. Sun, X. Yang, E. Tang, J. Wen, M. Lu, Q. Hu: The treatment of sublingual gland tumours. Int. J. Oral Maxillofac. Surg. 2010; 39: 863-868.

10. Matsuyama A, Hisaoka M, Nagao Y, Hashimoto H. Aberrant PLAG1 expression 
in pleomorphic adenomas of the salivary gland: a molecular genetic and immunohistochemical study. Virchows Archiv 2011Nov;458:583-92. [Medline]

11. Wittekindt C, Streubel K, Arnold G, Stennert E, Guntinas-Lichius O. Recurrent pleomorphic adenoma of the Consultant parotid gland: Analysis of 108 consecutive patients. Head \& Neck 2007;29:822-8.[Pubmed]

12. Gnepp DR. Malignant mixed tumors of the salivary glands: a review. PatholAnnu1993. 28:279-328. [Medline].

13. Soares AB, Demasi APD, Altemani A, Araújo VCD. Increased mucin 1 expression in recurrence and malignant transformation of salivary gland pleomorphic adenoma. Histopathology 2011;58:377-82.[Medline] 